\title{
Scleral Tunnel Fixated Intraocular Lens in Complicated Cataract: A Case Series
}

\author{
ST Lim ${ }^{a}$, M. H. Yong ${ }^{a}$, WAH Wan Haslina ${ }^{a}$, Mushawiahti $M^{a}$, Bastion MLC \\ ${ }^{a}$ Department of Ophthalmology, Universiti Kebangsaan Malaysia Medical Centre (UKMMC), Kuala Lumpur
}

\section{ABSTRACT}

When capsular support is inadequate in complicated cataract, scleral fixated IOL (SFIOL) has its advantage whereby it is nearer to physiological nodal point when compared to other types of IOL implantation. Scleral tunnel fixated intraocular lens (STFIOL) technique is gaining popularity due to its simplicity and ease of placement compared to sutured IOL. We report our experience with eight cases of STFIOL implantation from September 2016 to May 2018 in Universiti Kebangsaan Malaysia Medical Centre (UKMMC). All patients had improvement of vision except one case who had unchanged vision. Mean post-operative BCVA was logMAR $0.57 \pm 1.13$ (which is almost equivalent to 6/21) and improved to $\operatorname{logMAR} 0.37 \pm 0.43$ (which is almost equivalent to 6/12) excluding one patient with chronic RRD with band keratopathy. Post-op complications include raised intraocular pressure, cystoid macular oedema, hyphaema, and wound leak. However, all complications were not severe and responded to topical eyedrops. In conclusion, STFIOL insertion technique is safe and works well to restore vision in majority of patients operated with this technique.

KEYWORDS: Scleral tunnel fixated intraocular lens, sutureless scleral fixated intraocular lens, three-piece intraocular lens

\section{INTRODUCTION}

Inadequate capsular support for intraocular lens (IOL) implantation is not a rare encounter in ophthalmic surgery. Common causes of inadequate capsular support are ocular trauma, complicated cataract surgery and metabolic or inherited conditions such as Marfans syndrome and pseudoexfoliation. There are a few methods of visual rehabilitation secondary to inadequate capsular support including anterior chamber IOL (ACIOL), iris fixated IOL (IFIOL), and scleral fixated IOL (SFIOL). Each approach has its advantages and disadvantages. Many surgeons find ACIOL technique to be easier compared to other fixation methods. However, endothelial cell loss, corneal decompensation, secondary

\section{Corresponding Author:}

Prof. Dr. Mae-Lynn Catherine Bastion

Department of Ophthalmology

Universiti Kebangsaan Malaysia Medical Centre,

Jalan Yaakob Latif, Bandar Tun Razak

56000 Cheras, Kuala Lumpur

Malaysia.

Tel No: +603-91455981

E-mail : maelynnbdr@gmail.com glaucoma and recurrent uveitis are more common in ACIOL implantation. Recurrent uveitis, IOL dislocation or decentration and accelerated endothelial cell loss are more frequent with IFIOL. Therefore, some surgeons prefer SFIOL implantation. The position of the SFIOL is closer to the physiological nodal point and further from corneal endothelial cells. It also reduces the risk of injury to the iris and is preferred for patients with glaucoma. Limitations of this technique are mainly on the accuracy of IOL placement because the haptic fixation cannot be visualized behind the iris. In addition, it is time consuming, requires experience and skill with relatively more intraocular manipulations and scleral suturing in order to perform scleral sutured (SFIOL) technique, in which the SFIOL can be fixated in the ciliary sulcus by using a trans-scleral suture. The good visual outcomes with SFIOL have been offset by late onset of IOL rotation about the suture, suture breakage and IOL dislocation as well as rubbing of the lens against the iris due to its ability to rotate resulting in pigment dispersion and iritis. ${ }^{1,2}$ 
SFIOL can also be placed in the ciliary sulcus, by tucking the IOL haptic into scleral tunnel hence becoming scleral tunnel fixated IOL (STFIOL). Gabor et al. first introduced this technique in 2007.3 STFIOL avoids the need for a complex suturing procedure and is more stable by virtue of the haptic placements in scleral tunnels. A study comparing these two fixation techniques by Balakrishnan et al. in 68 eyes described similar visual outcome between glued STFIOL and transscleral sutured SFIOL. However, the operation time was significantly lower in the glued STFIOL group. ${ }^{4}$ Despite its introduction in 2007, STFIOL technique is not widely practised especially for anterior segment surgeons and publications on STFIOL are scarce. In Malaysia, this technique is still not widely practised yet. This is probably due to the fact that the technique requires manipulation of the IOL at the posterior segment (vitreous cavity) and special instruments are needed to aid in this technique. Hence, we present our series of STFIOL patients to report our early experience with this technique and the visual outcome.

\section{Patients and Methods:}

This is a retrospective review of eight patients who underwent STFIOL implantation for various indications from September 2016 to May 2018 in UKMMC. Age at surgery, ocular history, reason for inadequacy of capsular support, surgical technique, type of IOL, preand post-op visual acuity, post-op complication and follow up duration were analysed.

\section{Surgical Technique:}

Surgery was performed either under general anaesthesia or subtenon injection. Two vitreoretinal surgeons of more than 5 years' experience performed all surgeries (surgeon MWM and MLCB). The technique of tunnel creation and fixation varied due to surgeon's early experience with the techniques.

Surgeon MWM incorporated Yamane's technique5 in one of her latest case (case no. $3 \& 8$, Table 1 ). In this case, the conjunctiva was marked at 3 and 9 o'clock, 2 $\mathrm{mm}$ from the limbus. A bent $27 \mathrm{G}$ needle was used to create partial thickness scleral tunnels at 3 and 9 o'clock positions transconjunctivally. A three-piece IOL was inserted into the anterior chamber manually. While keeping the trailing haptic at the limbal wound, the leading haptic was threaded into the $27 \mathrm{G}$ needle lumen intraocularly using a $23 \mathrm{G}$ flat tip forceps. The leading haptic tip was then externalized by pulling out the $27 \mathrm{G}$ needle. Tip of the haptic was then cauterized with Straight Tip Battery Cautery (Precision Medical Specialities, Germany) to make a flange. The same procedure was repeated at 3 o'clock position for the trailing haptic. This technique saves a lot of time but it is more technically challenging.

On the other hand, surgeon MLB incorporated modified Prenner et al. technique 6 in her recent two cases (case no. $5 \& 6$, Table 1). She used a 20G MVR blade to create 2 sclerostomy wounds $180^{\circ}$ to each other, $2 \mathrm{~mm}$ from the limbus. Subsequently, a $25 \mathrm{G}$ needle or $23 \mathrm{G}$ vitrectomy trocar blade was used to create partial thickness scleral tunnel around 2-3 $\mathrm{mm}$ long, just adjacent to the sclerostomy wound. An AR40E SENSARTM (Johnson \& Johnson, United States) IOL was then inserted into anterior chamber manually via a superior corneal wound. The leading haptic was grasped and then externalized onto the sclera using Eckardt Power End Gripping 25G Forceps (DORC, Netherlands). The externalized haptic then was tucked into the scleral tunnel. The same procedure was done to externalize the trailing haptic. The sclerostomy wounds were sutured with a single interrupted Vicryl 80 stitch. The conjunctiva was then also closed with Vicryl 8-0. The surgeon found visualisation of the haptics in the tunnel more reassuring but this is the surgeon's preference.

\section{RESULTS}

Eight consecutive cases were included in this analysis. Median age was 69 years (range 11 to 83 years). The causes of inadequate capsular support were complicated previous surgery in five eyes $(62.5 \%)$, trauma in two eyes $(25 \%)$ and spontaneous IOL dislocation in one eye. Median surgery duration was 85 minutes (range 45-145 minutes). However, this surgery duration included combined vitrectomy and combined AC washout duration. One case was prolonged due to difficulty in removal of densiron oil from anterior chamber (case no. 1 on Table 1). Three cases (37.5\%) had combined anterior and posterior segment surgery (case no. 4, 6, 7 
on Table 1). One surgery (12.5\%) was combined with anterior chamber (AC) wash out of emulsified oil (case no. 1 on Table 1). Scleral flap was created in five eyes (62.5\%). The three-piece IOLs used were the AR40E SENSARTM (Johnson \& Johnson, United States) in seven eyes $(87.5 \%)$ and MN60AC (Alcon, United States) in one eye. Two eyes (20\%) had their haptics sutured in the tunnel.

\section{Surgery by surgeon MWM :}

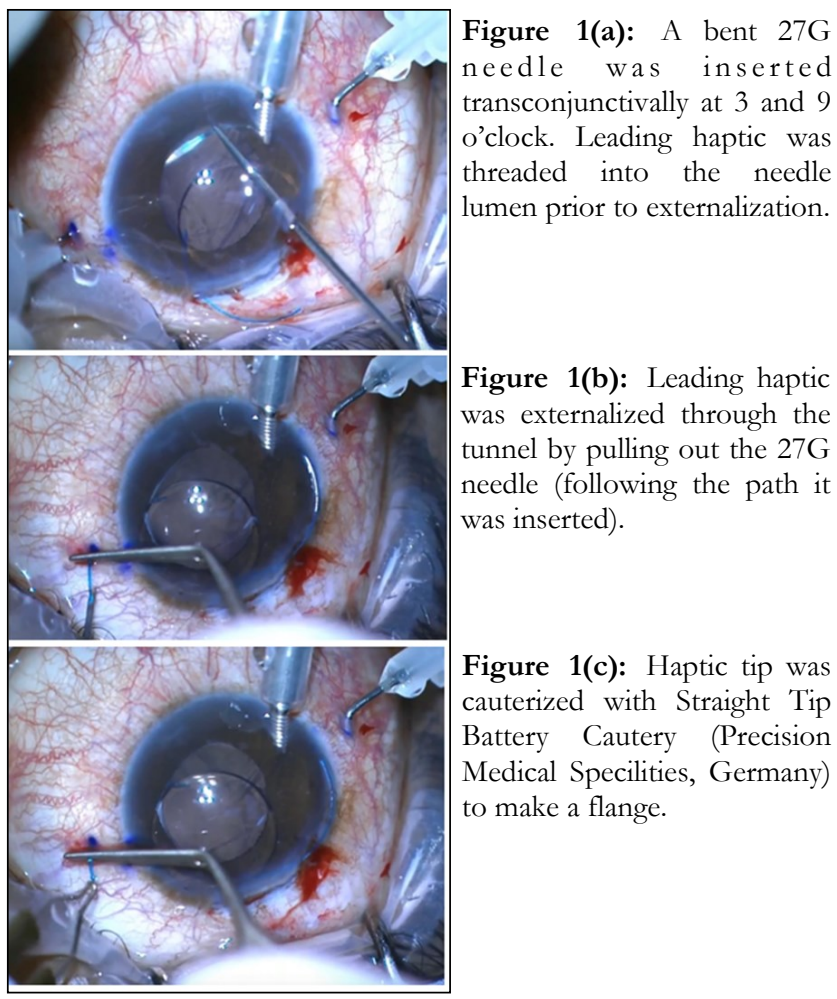

Duration of follow-up ranged from two weeks to 16 months, with seven patients $(87.5 \%)$ completing at least three months follow-up. Mean duration of follow up was 7.7 months. All patients had improvement of vision except one case who had unchanged vision. Even then, the vision was good at $6 / 12$ after surgery. One patient with underlying traumatic chronic rhegmatogenous retinal detachment (RRD) with band keratopathy had post operation VA of 1/60, which improved from hand movement (HM). Mean post-operative BCVA was $\log$ MAR $0.57 \pm 1.13$ (which is almost equivalent to $6 / 21$ ) and improved to $\operatorname{logMAR} 0.37 \pm 0.43$ (which is almost equivalent to $6 / 12$ ) excluding one patient with chronic RRD with band keratopathy. Post operatively, four eyes $(50 \%)$ had raised intraocular pressure (IOP) which was controlled with topical medications. Two of the patients' IOP returned to normal after one week and one month respectively. Two eyes had cystoid macular oedema which responded to topical NSAIDS. One patient had post-operative hyphaema and wound leak, which required re-suturing. There was no case of postoperative retinal detachment, vitreous haemorrhage or dislocated IOL. One eye had posteriorly tilted IOL, which was under observation.

\section{Surgery by surgeon MLCB:}

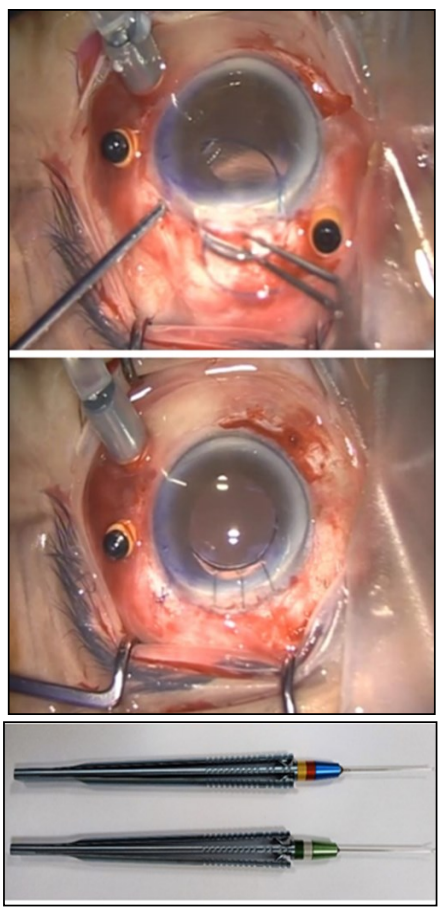

Figure 2(a): First haptic is being externalized using vitreoretinal forceps from sclerostomy wound.

\section{DISCUSSION}

STFIOL is one of the choices of visual rehabilitation in patients with inadequate capsular support. In our study, based on surgeons' preference, we incorporated a few techniques to varying degrees. In the initial five cases, our surgeons created partial thickness scleral flap to cover the IOL haptics as described by Agarwal et al. and Rodrigues et al.7,8 Subsequently, to shorten the surgical time, scleral flaps were not created in more recent three cases by both surgeons. IOL haptics were fully tucked into partial thickness limbus-parallel scleral tunnel. ${ }^{3}$ This technique is simpler and does not require any suture or fibrin glue.

To minimize the instruments needed for this sutureless STFIOL method, Yamane et al. introduced flanged intrascleral intraocular lens with transconjunctival needle technique.5 One of our surgeons (MWM) incorporated this technique in one case as described above. This technique provide less discomfort to patient in view of no conjunctival peritomy, minimalizing the instruments needed as well as shorter 
Table 1: Summary of the cases

\begin{tabular}{|c|c|c|c|c|c|c|c|c|c|}
\hline \multirow{3}{*}{$\begin{array}{l}\text { Age } \\
\text { (Year/ } \\
\text { Sex) }\end{array}$} & \multirow[t]{3}{*}{ Diagnosis } & \multicolumn{4}{|c|}{ VA } & \multirow{3}{*}{$\begin{array}{c}\text { Duration } \\
\text { of surgery } \\
\text { (min) }\end{array}$} & \multirow[t]{3}{*}{ Technique } & \multicolumn{2}{|c|}{ Complication } \\
\hline & & \multirow{2}{*}{$\begin{array}{l}\text { Pre- } \\
\text { op }\end{array}$} & \multicolumn{3}{|c|}{ Post-op } & & & & \\
\hline & & & $\begin{array}{c}\text { Day } \\
1\end{array}$ & $\begin{array}{c}\text { Day } \\
7\end{array}$ & $\begin{array}{c}\text { Day } \\
90\end{array}$ & & & & \\
\hline $111 / \mathrm{M}$ & $\begin{array}{l}\text { Surgical aphakia } \\
\text { (post cataract } \\
\text { surgery) with } \\
\text { underlying traumatic } \\
\text { chronic RRD with } \\
\text { band keratopathy }\end{array}$ & PL & $\mathrm{HM}$ & $\mathrm{N} / \mathrm{A}$ & $1 / 60$ & 145 & $\begin{array}{l}\text { Agarwal's } \\
\text { Technique }\end{array}$ & Nil & \\
\hline $\begin{array}{ll}2 & 67 / \mathrm{M}\end{array}$ & $\begin{array}{l}\text { Surgical aphakia } \\
\text { (post complicated } \\
\text { cataract surgery) }\end{array}$ & $1 / 60$ & $\mathrm{HM}$ & $6 / 36$ & $6 / 12$ & 90 & $\begin{array}{l}\text { Agarwal's } \\
\text { Technique }\end{array}$ & $\bullet$ & $\begin{array}{l}\text { Raised IOP (on } 2 \\
\text { topical anti- } \\
\text { glaucoma) } \\
\text { CMO (improved with } \\
\text { NSAID eyedrops) } \\
\end{array}$ \\
\hline $\begin{array}{ll}3 & 83 / \mathrm{M}\end{array}$ & $\begin{array}{l}\text { Subluxated IOL } \\
\text { (post complicated } \\
\text { cataract surgery) }\end{array}$ & $2 / 60$ & $\mathrm{HM}$ & $2 / 60$ & $6 / 36$ & 45 & $\begin{array}{l}\text { Yamane's } \\
\text { Technique }\end{array}$ & - & $\begin{array}{l}\text { Transient raised IOP } \\
\text { High astigmatism }\end{array}$ \\
\hline $\begin{array}{ll}4 & 52 / \mathrm{M}\end{array}$ & $\begin{array}{l}\text { Traumatic dislocated } \\
\text { IOL }\end{array}$ & $1 / 60$ & $\mathrm{HM}$ & $\mathrm{HM}$ & $6 / 24$ & 80 & $\begin{array}{l}\text { Agarwal's } \\
\text { Technique }\end{array}$ & $\begin{array}{l}\bullet \\
\bullet \\
\bullet \\
\bullet\end{array}$ & $\begin{array}{l}\text { Hyphaema } \\
\text { Wound leak } \\
\text { Transient raised IOP } \\
\text { Posteriorly tilted IOL }\end{array}$ \\
\hline $\begin{array}{ll}5 & 71 / \mathrm{F}\end{array}$ & $\begin{array}{l}\text { Surgical aphakia } \\
\text { (post complicated } \\
\text { cataract surgery) }\end{array}$ & $\mathrm{CF}$ & $6 / 12$ & $6 / 24$ & $6 / 9$ & 70 & $\begin{array}{l}\text { Prenner's } \\
\text { Technique }\end{array}$ & • & $\begin{array}{l}\text { Raised IOP (on } 1 \\
\text { topical anti- } \\
\text { glaucoma) }\end{array}$ \\
\hline $\begin{array}{ll}6 & 71 / \mathrm{F}\end{array}$ & $\begin{array}{l}\text { Spontaneous } \\
\text { subluxated IOL }\end{array}$ & $6 / 12$ & $\mathrm{~N} / \mathrm{A}$ & $6 / 24$ & $6 / 12$ & 90 & $\begin{array}{l}\text { Prenner's } \\
\text { Technique }\end{array}$ & Nil & \\
\hline $\begin{array}{ll}7 & 67 / \mathrm{M}\end{array}$ & $\begin{array}{l}\text { Traumatic dislocated } \\
\text { IOL }\end{array}$ & $\mathrm{CF}$ & $3 / 60$ & $6 / 36$ & $6 / 18$ & 90 & $\begin{array}{l}\text { Agarwal's } \\
\text { Technique }\end{array}$ & $\bullet$ & $\begin{array}{l}\text { CMO (improved with } \\
\text { NSAID eyedrop) }\end{array}$ \\
\hline $\begin{array}{ll}8 & 79 / \mathrm{M}\end{array}$ & $\begin{array}{l}\text { Subluxated IOL } \\
\text { (post complicated } \\
\text { cataract surgery) }\end{array}$ & $1 / 60$ & $6 / 36$ & $6 / 12$ & $6 / 9$ & 60 & $\begin{array}{l}\text { Yamane's } \\
\text { Technique }\end{array}$ & Nil & \\
\hline
\end{tabular}

CF: Counting finger, HM: Hand movement, PL: Perception to light

duration of insertion. However, this technique is challenging and might need relatively longer learning curve and almost precise placement of wounds for centrality of the lens.

Our result is consistent with many previous studies on STFIOL, including a study done by Abbey et al. in 23 patients with significant overall mean improvement in BCVA.9 Most of the patients achieved stable VA at 3 months post-op. Mean post-op BCVA in our study was $\log$ MAR $0.57 \pm 1.13$ which was worse than the previous study by Abbey et al. with mean post-op VA of logMAR 0.37.9 This is due to one of the patients having poor post-op VA due to underlying chronic RRD with band keratopathy. If this patient was excluded, the mean BCVA is improved to $\log$ MAR $0.37 \pm 0.43$. In our case series, some cases were combined surgeries, the median surgery time of 85 minutes could be made shorter if these combined surgeries (e.g. combined with vitrectomy) were not included in this case series. We were unable to retrieve the time of IOL implantation only due to lack of this detail in the operating record. This is a further limitation of this retrospective analysis. According to both our surgeons (MWM and MLB), the STFIOL technique is a time saver, if compared to the conventional sutured SFIOL technique, but not compared to ACIOL insertion which is faster but carries more complications in the long term and is not suitable for patients with glaucoma or inadequate iris support. It is also a cheaper technique if compared to conventional sutured SFIOL technique (a more affordable conventional 3-piece IOL with PMMA haptics for sulcus implantation is used instead of the specially designed limited supply IOL with eyelet in sutured SFIOL). To our knowledge, median duration of surgery was not analysed in previous literatures. Hence, we were unable to compare the duration of STFIOL surgery in our case series to sutured SFIOL.

Increased IOP and CMO were frequently mentioned as post-operative complications in previous similar 
studies9-12. In our study, increased IOP and CMO were among the most common complications occurring in four and two eyes respectively. These complications nonetheless appeared transient and were managed with topical medications. However, other post-operative complications in previous studies such as post-operative retinal detachment, vitreous haemorrhage or dislocated IOL were not seen in this study.

This study with long follow-up illustrates the good success and low complication rate attained with STFIOL which is a preferred IOL implantation technique rather than anterior chamber IOL or SFIOL for aphakia in UKMMC. There is to date no gold standard for STFIOL implantation technique and this study illustrates that reasonable results can be achieved with varying techniques that do not require special IOL or time consuming suturing. However, there is no head-to-head comparison between sutured SFIOL technique and STFIOL technique, which is a limitation of this retrospective case series. The heterogeneity of the technique used in STFIOL is another limitation of the study. It does however illustrate that modifications to the technique are many and still achieve the required visual rehabilitation in most cases.

Although the learning curve can be relatively steep, various approaches of suturing the externalized haptic are considered reasonably effective with no major issues. With proper instrumentations and precise surgical steps, the STFIOL insertion may become the treatment of choice for many surgeons.

In conclusion, STFIOL insertion technique is fairly safe. It provides favourable anatomical and visual outcome with the potential to eliminate many of the complications of conventional ACIOL and SFIOL implantation.

\section{REFERENCES}

1. Price MO, Price Jr FW, Werner L, Berlie C, Mamalis N. Late dislocation of scleral-sutured posterior chamber intraocular lenses. Journal of Cataract \& Refractive Surgery. 2005;31(7):1320-1326.

2. Vote BJ, Tranos P, Bunce C, Charteris DG, Da Cruz L. Long-term outcome of combined pars plana vitrectomy and scleral fixated sutured posterior chamber intraocular lens implantation. American journal of ophthalmology. 2006;141(2):308-312. e301.

3. Gabor SGB, Pavlidis MM. Sutureless intrascleral posterior chamber intraocular lens fixation. Journal of Cataract \& Refractive Surgery. 2007;33(11):1851 $-1854$.

4. Balakrishnan D, Mukundaprasad V, Jalali S, Pappuru RR. A Comparative Study on Surgical Outcomes of Glued Intraocular Lens and Sutured Scleral Fixated Intraocular Lens Implantation. Paper presented at: Seminars in ophthalmology, 2018.

5. Yamane S, Sato S, Maruyama-Inoue M, Kadonosono K. Flanged intrascleral intraocular lens fixation with double-needle technique. Ophthalmology. 2017;124(8):1136-1142.

6. Prenner JL, Feiner L, Wheatley HM, Connors D. A novel approach for posterior chamber intraocular lens placement or rescue via a sutureless scleral fixation technique. Retina. 2012;32(4):853-855.

7. Agarwal A, Kumar DA, Jacob S, Baid C, Agarwal A, Srinivasan S. Fibrin glue-assisted sutureless posterior chamber intraocular lens implantation in eyes with deficient posterior capsules. Journal of Cataract \& Refractive Surgery. 2008;34(9):14331438.

8. Rodríguez-Agirretxe I, Acera-Osa A, Ubeda-Erviti M. Needle-guided intrascleral fixation of posterior chamber intraocular lens for aphakia correction. Journal of Cataract \& Refractive Surgery. 2009;35 (12):2051-2053.

9. Abbey AM, Hussain RM, Shah AR, Faia LJ, Wolfe JD, Williams GA. Sutureless scleral fixation of intraocular lenses: outcomes of two approaches. The 2014 Yasuo Tano Memorial Lecture. Graefe's Archive for Clinical and Experimental Ophthalmology. 2015;253(1):1-5.

10. Wilgucki JD, Wheatley HM, Feiner L, Ferrone MV, Prenner JL. One-year outcomes of eyes treated with a sutureless scleral fixation technique for intraocular lens placement or rescue. Retina. 2015;35(5):1036-1040.

11. Scharioth GB, Prasad S, Georgalas I, Tataru C, Pavlidis M. Intermediate results of sutureless intrascleral posterior chamber intraocular lens 
fixation. Journal of Cataract \& Refractive Surgery. 2010;36(2):254-259.

12. Sindal MD, Nakhwa CP, Sengupta S. Comparison of sutured versus sutureless scleral-fixated intraocular lenses. Journal of Cataract \& Refractive Surgery. 2016;42(1):27-34. 